\title{
Understanding and Preventing Youth Cyberbullying in China: Causes, Effects, and Prevention
}

\author{
Yiyi Xue ${ }^{1}$ \\ ${ }^{1}$ Dana Hall School, Wellesley, MA \\ Correspondence: Yiyi Xue. E-mail: yiyi.xue@danahall.org
}

Received: May 18, 2018

Accepted: July 12, $2018 \quad$ Online Published: August 31, 2018

doi:10.5539/ass.v14n9p47

URL: https://doi.org/10.5539/ass.v14n9p47

\begin{abstract}
Although bullying is hardly a new phenomena, the development of digital technology has granted bullies easy access to social media and other platforms that have perhaps made victims of bullying more susceptible than ever before. An analysis of existing scholarship and original statistical research was conducted to understand the frequency and severity of online harassment among teenagers in China. This paper examines the phenomenon of cyberbullying, the current social experience of Chinese teenagers, and potential ways to both assist teenage victims of cyberbullying and prevent online harassment in the future.
\end{abstract}

Keywords: youth cyberbullying, China, causes and effects, prevention

\section{Introduction}

\subsection{The Seriousness of Youth Cyberbullying in the Society Nowadays}

A large percentage of teenagers today have been exposed to bullying and harassment on social media. Data from the United States government shows that $28 \%$ of U.S. students in grades 6-12 have experienced online bullying, and $20 \%$ of U.S. students in grades 9-12 have experienced online bullying ("Facts about", 2017). The data reflects that both children and teenagers are exposed to cyberbullying significantly. Furthermore, another study on youth's use of social network platforms shows that, among those teenagers who reported experiencing cyberbullying, $72 \%$ reported they were bullied due to their appearance, $26 \%$ were bullied for their race or religion, and 22\% were bullied for their sexuality (Eichorn \& Ross, 2014). Of those who witnessed others being cyberbullied, $53 \%$ responded that the victims became defensive or angry, and $47 \%$ said that the victims deleted their social media accounts after the incident, underscoring the significant emotional impact of social media harassment on teenagers (Eichorn \& Ross, 2014). Existing research thus demonstrates that a substantial number of youth experience cyberbullying and its associated psychological trauma. Youth victims are likely to experience loneliness and social isolation, which leads to low self-esteem and depression (Cowie, 2013). As a whole, these statistics reflect a tragic reality: cyberbullying among youth occurs with great frequency, for a variety of reasons, and with severe negative outcomes. The most significant finding from a 2017 U.S. national survey reveals that $87 \%$ of youth have witnessed cyberbullying; last year, the percentage of youth who witnessed cyberbullying was only $27 \%$ (The Turkish, 2018). As such, it appears that the problem of youth cyberbullying is on the rise and will likely only grow in the future.

\subsection{Lack of Research on Youth Cyberbullying in China}

While cyberbullying remains a common phenomenon in society today, the practice and the effects of cyberbullying among youth is understudied amongst Chinese youth. Because of the stressful Gaokao, the Chinese national college entrance exam that takes place in June each year, the Chinese educational system focuses mainly on stringent academic programs, and it does not take time to teach students conflict resolution, effective communication, or how to intervene during instances of online harassment (Zhao, Selman, \& Haste, 2015). As a result, teachers, parents, and educators lack comprehensive knowledge about cyberbullying and how to combat it. Additionally, according to Global Times ("270 Million", 2017), China's youth Internet users reached 277 million in 2017, indicating that a vast number of Chinese youth are positioned to engage in cyberbullying or be a victim. However, because of limited research on cyberbullying in the Chinese context, it is unclear how Chinese youths protect themselves or seek help when experiencing cyberbullying. The goal of this research study is to explore ways to prevent the practice of cyberbullying. 


\section{Data and Methods}

This research study administered three questionnaire surveys over the course of six months. The first was a small and informal survey that the author gave to a small group of high school students to acquire some primary knowledge about teenagers' ideas on emotional violence through social media. There were ten questions on the survey, in multiple choice and free response format, and 68 people answered it over the course of two weeks. The second questionnaire contained twenty questions and served as a preliminary questionnaire for a final survey with a much larger data pool. This second survey was published on Wen Juan Xing, a website that helps people to collect survey results, and 54 people filled out the survey over two days. Based on the second survey, questions were revised and sent out in the form of a third questionnaire on Wen Juan Xing. 529 people completed the third survey, and the age of the surveyors ranged from twelve to twenty-two years old.

\section{Analysis and Results}

In the first survey, $52.9 \%$ of the people surveyed stated that they check their phone whenever they have free time. $42.6 \%$ of those surveyed reported that they have either experienced or have seen cyberbullying in their daily lives. $94.1 \%$ reported that they hope to do something positive on social media, which shows that the chaotic and aggressive online environment could be changed if we helped teenagers to conduct themselves positively on the internet.

In the second survey, $88.89 \%$ of people stated that they believe cyberbullying happens more often between strangers, reflecting how people find it easier to bully people they do not know online. Later in the free response section, the surveyors indicated that they do not need to worry about many of the severe consequences that would come with face-to-face aggression when they are online surfing. Tragically, even though cyberbullying happens very often among teenagers, $57.41 \%$ of the surveyors conveyed that their parents and teachers had never taught them anything about cyberbullying, and $92.59 \%$ of people stated that they learned cyberbullying through social media such as news on television and newspaper. Furthermore, $74.07 \%$ of the surveyors reported that they would tell their friends about their cyberbullying experience. In contrast, only $14.81 \%$ of people said that they would tell their teachers, and $33.33 \%$ of people would tell their parents. Similar to the first survey, $98.15 \%$ of people reported that they believe society should focus more on the causes and effects of cyberbullying. Most of them put down the reason of their choice because they believe by learning the causes and effects of cyberbullying people in general, but especially teenagers, will not have to face this trauma in the future.

In the third survey, respondents were asked to rate the severity of the cyberbullying that they have experienced or witnessed, with one representing the least serious, and five representing the most serious. The average score is 3.41 with 103 people rating their experience as a five. Another question asks the parents of those surveyed to rate the severity of the cyberbullying event they witnessed. The average score is 3.58 with 153 parents reporting a score of five. This represents a significant increase: 50 more parents than students gave a score of 5 . Furthermore, $75.99 \%$ of students surveyed say that they would tell their friends or classmates about their bullying experience, but only $39.32 \%$ claim that they would confide in their parents about the experience. Ultimately, $98.3 \%$ of those surveyed believe that cyberbullying is a significant social issue in China.

\section{Conclusion}

These findings provide evidence describing the occurrence of cyberbullying in China, and they also suggested potential pathways for cyberbullying prevention in the Chinese context.

Results from the first survey show that Chinese teenagers spend a lot of time on social media every day. Results from the second survey reflect the tragic fact that schools in China are focusing entirely on academics and neglecting to teach students skills relating to conflict resolution, which leads to widespread ignorance about cyberbullying. Devoting more time to the causes and effects of cyberbullying may help the teenagers to recognize the harm of it and eliminate destructive behaviors. In the third survey, the average score of parents is much higher than that of the children's. This may because that teenagers have a different perception of cyberbullying compared to adults. It may also be due to the parents' and teens' differing levels of experience with cyberbullying: students may have witnessed more cyberbullying and have a different perspective on the range of severity.

Cyberbullying occurs very frequently among teenagers living in the digital era, and the issue requires more attention from adults in China in order to help teenage victims and prevent cyberbullying from occurring in the future. Teenagers can certainly be better educated about cyberbullying, and even small efforts may make a significant impact on children's lives. Teachers and parents are likely to be effective leaders in this respect given that children spend most of their time with these two groups of adults specifically and children tend to mimic 
adults' behaviors (Pownall, 2018). For example, the Chinese teachers and parents could model inclusive and friendly behavior even when they have differing opinions with others online, and they could constantly teach the children about how to solve the conflicts peacefully. As children observe adults' friendly actions, they may mimic this behavior in their online interactions and learn to control their anger and express their ideas in kinder way. By doing so, adults can show the children in their lives that there is no place for bullying in a civilized society. Furthermore, in some cases, children choose to bully others because they have trouble managing strong emotions like anger, frustration, or insecurity. In these instances, discussing bullying with children may be beneficial for building their emotional intelligence and ability to cooperate with others (Lyness, 2013). Chinese schools could provide students with school-based verbal and emotional violence prevention programs, which can help students identify cyberbullying, learn how to protect themselves and their peers from cyberbullying, and identify how to seek help. If students know the true definition of online harassment and cyberbullying, and they know that they have the support of the community at large, children will suffer less victimization on social media.

\section{References}

Cowie, H. (2013). Cyberbullying and its impact on young people's emotional health and well-being. The Psychiatrist, 37(5), 167-170. https://doi:10.1192/pb.bp.112.040840

Eichorn, Kim, \& Ross, E. (2014). Cyberbullying Triples According to New McAfee '2014 Teens and the Screen Study.' McAfee. Retrieved from https://www.mcafee.com/us/about/news/2014/q2/20140603-01.aspx

Global Times. (2017). 270 Million Chinese Youth Use the Internet. Retrieved from http://www.globaltimes.cn/content/1067369.shtml

Lyness, D. (2013). Teaching Kids Not to Bully. Kids Health. Retrieved from https://kidshealth.org/en/parents/no-bullying.html

Pownall, S. (2018). We Suffer for Rest of Our Lives Bullies Just Move to New Victims; Battle for Law Change after Son's Suicide; Mum's Turmoil as Inquest Says no Charges from Death; Dail Debate on Social Media after Torment of Darren, 17; Exclusive. Sunday Mirror [London]. Gale, go.galegroup.com.

Stopbullying, U.S. Department of Health and Human Services. (2017). Facts about Bullying. Retrieved September 28, 2017, from https://www.stopbullying.gov/media/facts/index.html\#stats

The Turkish Newswire [Lahore] (2018). Quarter of Turkish Youths Exposed to Cyber Bullying: Technology Authority, go.galegroup.com.

Zhao, X., Selman, R. L., \& Haste, H. (2015) Academic stress in Chinese schools and a proposed preventive intervention program. Cogent Education, 2(1). https://doi:10.1080/2331186X.2014.1000477

\section{Copyrights}

Copyright for this article is retained by the author(s), with first publication rights granted to the journal.

This is an open-access article distributed under the terms and conditions of the Creative Commons Attribution license (http://creativecommons.org/licenses/by/4.0/). 